\title{
Analysis of Problem Solving on the Argumentation Ability of Students Under the Topic of Dynamic Electricity
}

\author{
Laily Rosdiana*, Martini, Siti Nurul Hidayati, Ahmad Qosyim, and Roihanna Waliyyul Mursyidah \\ Science Education, Science Department, Surabaya, Indonesia.
}

\begin{abstract}
This study aims to determine student problem solving on students' argumentation skills under the topic of dynamic electricity. Design in this research is descriptive-qualitative and using a case study design with 34 undergraduate students who were selected using purposive sampling technique. The data was obtained through an essay test which consisted of 3 questions using the right arguments. The results of this research show that the percentage level of argumentation categories sequentially increases in each category. For category 1 it is $6 \%$, category 2 is $24 \%$, category 3 is $26 \%$ and category 4 is $44 \%$. The results of the student's argumentation show that their argumentation ability is still relatively low, which is below $50 \%$.
\end{abstract}

Keywords: Problem solving, Dynamic electricity, Argumentation

\section{Introduction}

Among the important skills of the $21 \mathrm{st}$ century collaboration and problem solving are important skills that must be mastered, because both skills can be fostered and developed through a problem-solving approach in mathematics or called teaching through problem solving [2].

Nowdays, humans naturally solve problems in their life to fulfil various necessity. According problem solving is practiced in schools as well [9], because one of its main goals is to train students to solve problems, both problems in the school context and problems in daily life. Therefore, in identifying problem situations, assessing possible implications, and finding solutions to avoid various consequences or at least reduce their impact on the environment, it is very important to solve. Problem solving is the initial knowledge of people who are given a conditioning and a process to overcome obstacles that must be overcome not only including cognitive aspects but also motivational and emotional aspects [4]. The typical phase according to prior research which are used to solve problems, among others, the discovery of problematic situations, the resolution process in which the subject can change the situation/object under study to meet the required objectives, verification of the methods found [5]. Problem solving is described as a result of resume of activity such us knowing problem, interpreting problem, figuring out problem, choosing the appropriate strategy, applying the process and strategy skill, and making written and acceptable answers. Based on the opinion of the researchers above, the essence of problem solving is a person's activity to be able to solve problems appropriately and acceptable through certain conditioning strategies.

Specifically in this study, the problem solving test using argumentation skills is a new concept understanding test in the Science Education Study Program where the lecturer as a researcher uses this test as part of the intervention. The concept understanding test in this study was used on dynamic electricity material. Several studies have shown that students still cannot understand the characteristics of the test with their own answers without any examples or instructions [3]. According to another research suggest that an unexplored study is how to investigate students when answering problem-solving questions on the topic of Electricity and Magnetism [7].

Scientific argumentation can be seen structure and a dialogical process. In terms of structure, it is considered a framework that includes claims, evidence, and reasons [1]. Another researcher describes argumentation as evidence and theory which form a coordination to support or refute modifier conclusion, model or prediction [8]. There are three reasons why argumentation is important in learning, (1) scientists use argumentation in developing their scientific knowledge ; (2) society uses argumentation in scientific debates ; (3) to strengthen their understanding, students need arguments in learning.

The researcher also found that there were difficulties in the application process of argumentation to certain models [11], and it was hoped that students would be more accustomed to using other science teaching models through the application of argumentation in other subjects. In this study, the problem-solving test was further strengthened by argumentation skills involving essay questions. By utilizing a problem-

*Corresponding author: lailyrosdiana@unesa.ac.id 
solving approach using argumentation skills, it is expected to be able to improve students' conceptual understanding by providing opportunities for students to knit daily life experiences with scientific concepts, thereby increasing students' understanding of concepts in solving problems that are relevant in life.

Specifically, the purpose of this research determines the effect of student problem solving which is enhanced by argumentation skills on students' understanding of concepts in Dynamic Electricity.

\section{Method}

A case study design with the descriptive qualitative data is the design of this research. Specifically, this study uses a heterogeneous class. The research sample involved 34 students of the 2018 batch. The students had taken the Dynamic Electricity course. The stages in this research consist of the initial stage, the core stage and the final stage. Observation, research design, and preparation of instruments are part of the initial stage. The core stage of the activities carried out was to test students by giving essay writing tests in the form of problem solving problems with Dynamic Electricity material on argumentation skills. The final stage is analyzing the data obtained in accordance with the analysis method and then making conclusions from the data.

The results of the problem-solving tests carried out by students will be obtained based on the assessment rubric as a determination of whether or not the criteria for argumentation ability have been met. The results of the data will be presented in the form of a percentage score.

Table 1. Assessment of the arguments on the polythemus scale

\begin{tabular}{|c|l|}
\hline Category & \multicolumn{1}{|c|}{ Description } \\
\hline Category 1 & $\begin{array}{l}\text { If the students interpret the concept } \\
\text { wrongly and their results is wrong, it is } \\
\text { shown when the students answer both } \\
\text { their answer and argumentation are } \\
\text { wrong. }\end{array}$ \\
\hline Category 2 & $\begin{array}{l}\text { If the students interpret the concept } \\
\text { wrongly and their results may be correct, } \\
\text { it is shown when the students answer } \\
\text { question correctly and give wrong } \\
\text { argumentation. }\end{array}$ \\
\hline Category 3 & $\begin{array}{l}\text { If the students can provide the correct } \\
\text { concept which is used in their answer, but } \\
\text { their result is wrong, it is shown when the } \\
\text { students can answering question wrongly } \\
\text { giving the correct argumentation. }\end{array}$ \\
\hline Category 4 & $\begin{array}{l}\text { If the students can provide both concept } \\
\text { and result correctly, it is shown when the } \\
\text { students can answering question correctly } \\
\text { and give the correct argumentation. }\end{array}$ \\
\hline
\end{tabular}

\section{Result And Discussion}

It was found from the data analysis that the average problem-solving test results for S1 Science Education Study Program students were in the medium category level. Because most students are confused in applying the concepts of knowledge, they have in solving problems. The search for problem-solving skills in argumentation skills was carried out based on low, medium and high categories.

The data analyzed is the result of the argumentation ability of each answer. The distribution of respondents' answers for each representation is presented in the table below.

Table 2. Scored based on scoring rubrics and representation indicators

\begin{tabular}{|c|c|}
\hline \multirow{2}{*}{ No } & Argumentation Ability \\
\hline & Category $(1,2,3,4)$ \\
\hline 1 & 2 \\
\hline 2 & 4 \\
\hline 3 & 3 \\
\hline 4 & 3 \\
\hline 5 & 1 \\
\hline 6 & 2 \\
\hline 7 & 4 \\
\hline 8 & 3 \\
\hline 9 & 2 \\
\hline 10 & 4 \\
\hline 11 & 3 \\
\hline 12 & 2 \\
\hline 13 & 3 \\
\hline 14 & 3 \\
\hline 15 & 3 \\
\hline 16 & 2 \\
\hline 17 & 4 \\
\hline 18 & 4 \\
\hline 19 & 4 \\
\hline 20 & 4 \\
\hline 21 & 3 \\
\hline 22 & 4 \\
\hline 23 & 4 \\
\hline 24 & 2 \\
\hline 25 & 4 \\
\hline 26 & 4 \\
\hline 27 & 3 \\
\hline 28 & 4 \\
\hline 29 & 4 \\
\hline 30 & 1 \\
\hline 31 & 4 \\
\hline 32 & 2 \\
\hline 33 & 2 \\
\hline 34 & 4 \\
\hline
\end{tabular}

Regarding students' argumentation skills, it can be seen in figure 1 below.

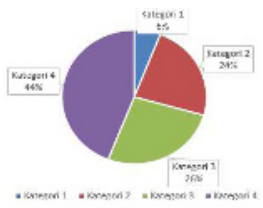

Fig. 1. Graph os students' argumentation ability categories. 
The percentage of average scores obtained by students in the argumentation category level 1 is $6 \%$, category 2 is $24 \%$, category 3 is $26 \%$ and category 4 is $44 \%$. The following is an excerpt of the reasons for the student's argument.

a. Question number 1

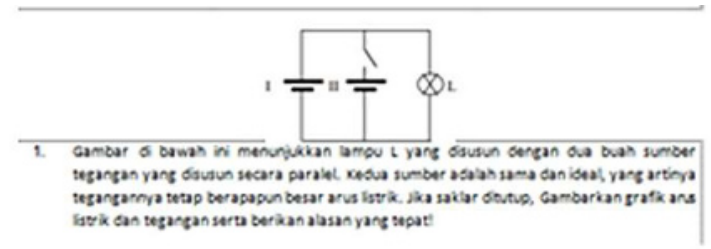

Fig. 2. Question number 1

This question is represented in visual and verbal form, accompanied by quotations of reasons and argumentative abilities, which can be seen in the image below.

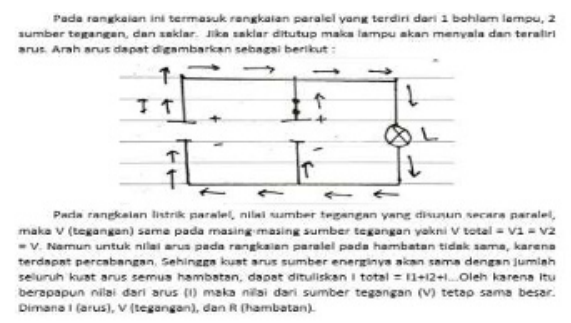

Fig. 3. Result of students' answer for question number 1

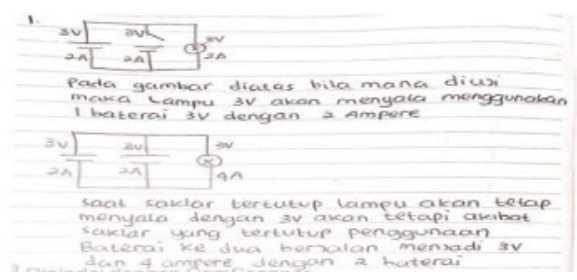

Fig. 4. Result of students' answer for question number 2

It can be seen that the respondents did not understand the visual representation in the form of a graph that was asked for in the question, while there were still some who did not understand the argumentation.

\section{b. Question number 2}

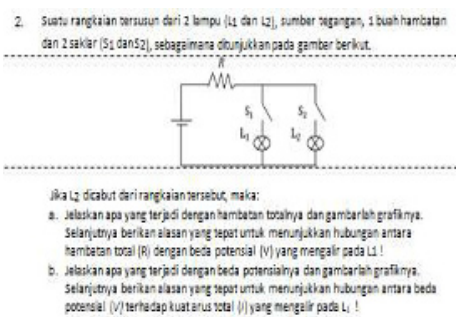

Fig. 5. Question number 2

This question is represented in visual and verbal form, accompanied by quotations of reasons and argumentative abilities, which can be seen in the image below

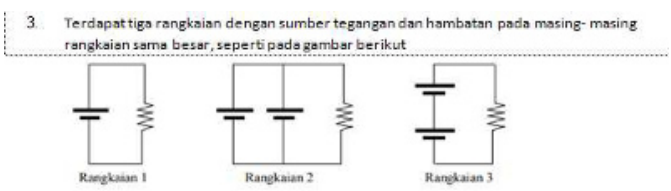

Jelaskan besar hambatan (R) pada masing-masing rangkaian dan gambarl loh gr afik hambatan
pada rangkalan tersebut!

Fig. 6. Result of students' answer for question number 2
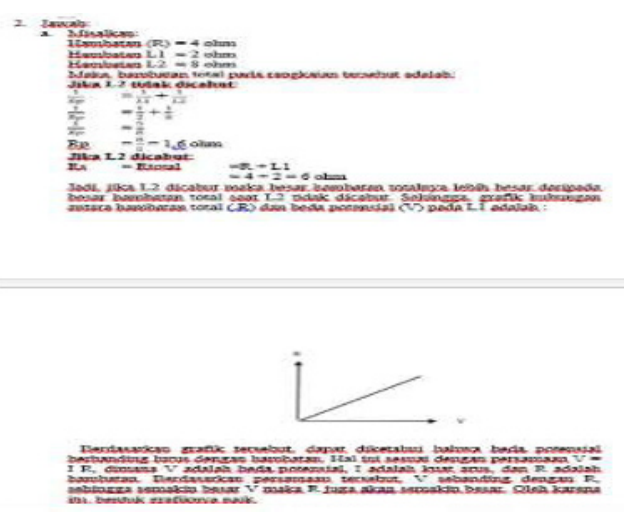

Fig. 7. Result of students' answer for question number 2

It can be seen that the respondent has begun to understand the visual representation in the form of a graph that is asked for in the question, while his argumentation has begun to be quite good at making his argument.

c. Question number 3

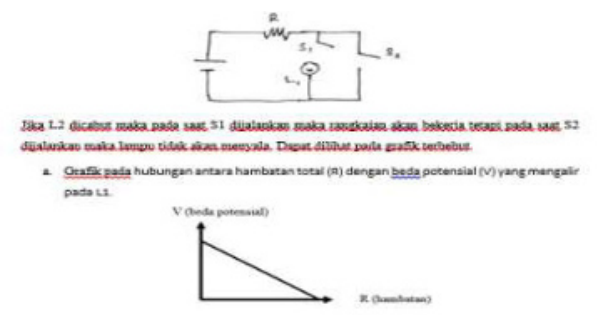

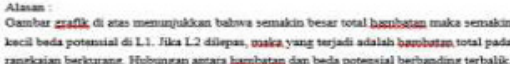


Fig. 8. Question number 2

This question is represented in visual and verbal form, accompanied by quotations of reasons and argumentative abilities, which can be seen in the image below.

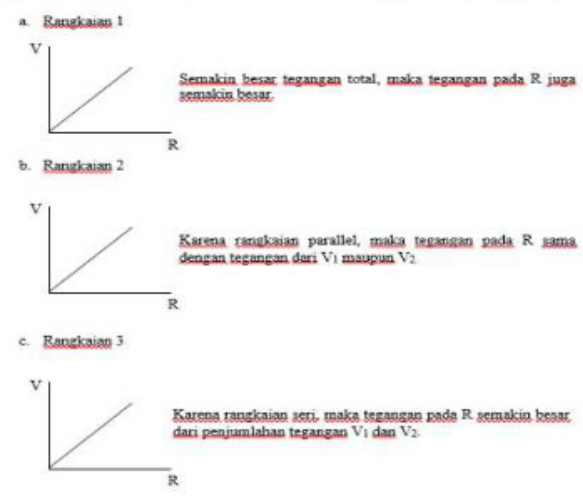

Fig. 9. Result of students' answer for question number 3
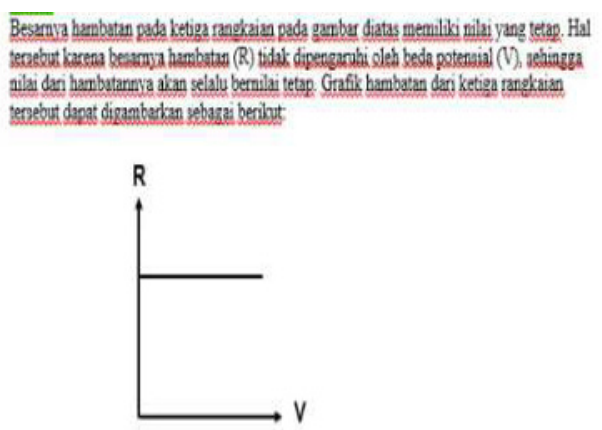

Fig. 10. Result of students' answer for question number 3

It is known from the result of the study the argumentation ability and students' external representation ability are still relatively low. It is shown from low percentage score of the graph/diagram presentation indicators. The biggest factor that causes students' ability in problem solving tests is the difficulty in applying the concepts of knowledge they have in solving problems. In order to generate conceptual understanding and apply the concept students must be aware of the relationship between cause and effect relationships ; expressing their doubts, presenting alternatives and the argumentation process can help to achieve this goal [11]. So, it can be said that students' argumentation and problem-solving abilities influence each other.

This argumentation ability requires students to be able to understand the relationship between claims and evidence which helps develop scientific process skills including problem solving activities. Seeing an event from the different perspectives and put forward different solutions is a fundamental thing in scientific process.[6].
Therefore, the ability of argumentation will be very influential in solving problem solving. In addition, this ability is an essential factor that must be mastered by prospective physics teachers as a requirement in explaining good and appropriate scientific concepts.

The result show the average argumentation ability of students was still low to moderate. Though this ability is needed in problem solving. This results parallel with prior research, that argumentation comes from rational thinking and critical thinking which are aspects of the problem solving process [1]. In his research, it was also found that the respondent's scientific argumentation ability was at the level of providing weak claims with guarantees (reasons). It can be concluded that most of the respondents are not able to provide appropriate rebuttal.

Overall problem solving with argumentation skills is closely related. The ability to argue is needed in confirming the reasons for making decisions (solutions) in the form of verbal, thereby increasing the validity and firmness of the solutions offered in the problem being solved.

\section{Closure}

\subsection{Conclusion}

From all of the explanations in the above, it can be concluded that the students' argumentation skills in problem solving are in the low category close to medium. This is because there are difficulties in analyzing the questions given and there are arguments that do not match the concept. Problem solving, especially Dynamic Electricity material, requires high analysis with student arguments that must be in accordance with the concept

\subsection{Suggestion}

Based on the conclusion, it is hoped that it can be considered that physics teachers also need to use appropriate argumentation skills in solving all problems in other physics materials.

\section{References}

[1] Ain, et al, The scientific arguments profile of physics teacher candidate in surabaya, J. Phys : Conference Series, (2018)

[2] Albay, E. M, Analyzing the effects of the problem solving approach to the performance and attitude of first year university students. Soc. Sci. Hum 1, (2019)

[3] Coleoni, E., \& Buteler, L, Students thinking during physics problem solving: Identifying the resources with which they learn. J. Sci. Educ 10, 1 10-14 (2009) 
[4] Csapó, B., \& Funke, J, The nature of problem solving. Using research to inspire 21st century learning. (2017)

[5] Dostál, J. Theory of Problem Solving. Proc. Soc. Behav. Scie, 174 2798-2805 (2015)

[6] Erduran, S., Simon, S., \& Osborne, J, Tapping into argumentation: developments in the application of Toulmin's argument pattern for studying science discourse. Sci. Edu 88, 6 915-933 (2004)

[7] Nehru, Riantoni, C., Rasmi, D. P., Kurniawan, W., \& Iskandar, Knowledge in pieces" view: conceptual understanding analysis of pre-service physics teachers on direct current resistive electrical circuits, J. For. The. Edu. Gifted. Young. Sci 8, 2 723-730 (2020).

[8] Osborne, J., Erduran, S., \& Simon, S, Enhancing the quality of argumentation in school science, J. Res. Sci. Teach 41, 10 994-1020 (2004)

[9] Permatasari, A. K., Istiyono, E., \& Kuswanto, H, Developing assessment instrument to measure physics problem solving skills for mirror topic, Inter. J. Educ. Res. Rev, 358-366 (2019)

[10] Singh, P., Rahman, A. A., \& Hoon, T. S, The newman procedure for analyzing primary four pupils errors on written mathematical tasks: a malaysian perspective, Proc. Soc. Behave. Sci 8, 264-271 (2010)

[11] Ural, E., \& Gençoğlan, D. M, The effect of argumentation-based science teaching approach on 8th graders' learning in the subject of acidsbases, their attitudes towards science class and scientific process skills, J. Enviro. Sci. Educ 16, , 1 (2019) 